\title{
Delay integro differential equations solutions with Euler polynomials method
}

\author{
Deniz Elmacl ${ }^{1}$ and Nurcan Baykuş Savaşaneril ${ }^{2}$ \\ ${ }^{1}$ Dokuz Eylul University, Bergama Vocational School, Izmir, Turkey. \\ ${ }^{2}$ Dokuz Eylul University, Izmir Vocational School, Izmir, Turkey.
}

Received: 9 May 2021, Accepted: 20 May 2021

Published online: 12 September 2021.

\begin{abstract}
In this study, a matrix-collocation method is applied to obtain the approximate solutions of integro-differential equations with variable delays by a truncated Taylor series. In the method, the functions and the coefficients in the problem are represented in the matrix form and the problem is reduced into an algebraic equations system. Then this algebraic system is solved by a code written in MATLAB in order to find approximate solutions. Besides, by using residual function, an error analysis technique with error estimation has been performed to improve the approximate solutions. On the other hand, the numerical examples along with tables and figures are given to illustrate validity and the applicability of the method and the obtained results are compared with the existing methods in literature.
\end{abstract}

Keywords: Euler polynomials, Collocation points, Residual error analysis, Variable delay, Proportional delay.

\section{Introduction}

Delayed Differential Equations (DDEs) were first introduced by Laplace and Condorcent in the 18th century. Later, Volterra in the elastic theory in 1909 and the delayed predator model in his own book in 1928-1931, Lotka and Sharpe in the model of the spread of infectious diseases in 1923, Kostyzin in the mathematical biology problem in 1934, Callender and Stevenson in the instability of delayed systems in 1936, Gorelik in 1939 on the microwave oscillator, Voznesensky and Solodovnikov in 1934 and 1941 on the effect of hydroshock on turbine stability and in the same year Bogomolov on the feedback system for hydroelectric power plants, Siever on the response of the cell to radiation irradiation, Andronov and Mayer on the delay in feedback systems in 1946, Kabakov and Sokolov were used in steam output control in 1946, and Gerasimov in feedback systems for heat transfer in 1949. Delay integro - differential equations (DIDEs) are usually used in the many phenomena in various sciences in the fields of engineering, mechanics, physics, chemistry, astronomy, biology, economics, potential theory, and electrostatics $[1,2,3,4,5,6]$. Recently, there has been a growing interest in the numerical solution of (DIDEs). The (DIDEs) have been solved by using some methods such as: Taylor collocation, Chebyshev collocation, Chebyshev-Lobatto collocation, Lagrange collocation, Jacobi collocation, operational Tau, Boubaker collocation and Muntez-Legendre matrix methods etc. [1,6,7,10,11,12,13,14,15,16,17,18]

In this study, we consider the m-th order linear Volterra-Fredholm integro-differential equation with delay term in the form

$$
\begin{aligned}
\sum_{k=0}^{m} P_{k}(t) y^{(k)}(t)+\sum_{r=0}^{m_{1}} Q_{r}(t) y^{(r)}\left(\alpha_{r} t+\beta_{r}(t)\right)=g(t)+ & \lambda_{1} \sum_{j=0}^{m_{2}} \int_{a}^{b} K_{j}^{f}(t, s) y^{(j)}\left(\tau_{j} s+\xi_{j}\right) d s \\
& +\lambda_{2} \sum_{p=0}^{m_{3}} \int_{u_{p}(t)}^{v_{p}(t)} K_{p}^{v}(t, s) y^{(p)}\left(\gamma_{p} s+\theta_{p}\right) d s
\end{aligned}
$$


with condition

$$
\sum_{k=0}^{m-1}\left(a_{j k} y^{(k)}(a)+b_{j k} y^{(k)}(b)\right)=\mu_{j}, j=0,1, \ldots, m-1
$$

where $P_{k}(t), Q_{r}(t), \beta_{r}(t), g(t), K_{j}^{f}(t, s), K_{r}^{v}(t, s), u_{p}(t)$ and $v_{p}(t)$

$\left(m_{1}, m_{2}, m_{3} \leq m, u_{p}(t)<v_{p}(t)\right)$ are functions defined on the interval $a \leq t \leq b ; \tau_{j}, \xi_{j}, \gamma_{p}, \theta_{p}, a_{j k}, b_{j k}$ and $\mu_{j}$ are appropriate constants; $y(t)$ is an unknown solution function to be determined. If $\lambda_{2}=0$, Eq.(1) becomes the Fredholm integro differential equation with delay term. If $\lambda_{1}=0$, it becomes the Volterra integro differential equation with delay term.

Our aim is to find an approximate solution of Eq.(1) expressed in the truncated Euler series form

$$
y(t) \cong y_{N}(t)=\sum_{n=0}^{N} a_{n} \mathrm{E}_{n}(t), \quad a \leqslant t \leqslant b
$$

where $E_{n}(t)$ indicates the Euler-Taylor polynomials which are described as

$$
\frac{2 e^{x t}}{e^{t}+1}=\sum_{n=0}^{\infty} E_{n}(x) \frac{t^{n}}{n !}, \quad|t|<\pi
$$

Euler polynomials are strictly connected with Bernoulli ones, and are used in the Taylor expansion in a neighborhood of the origin of trigonometric and hyperbolic secant functions. Recursive computation of Euler polynomials can be obtained by using the following formula [8];

$$
E_{n}(t)+\sum_{k=0}^{n}\left(\begin{array}{l}
n \\
k
\end{array}\right) E_{k}(t)=2 t^{n}, \quad n=1,2, \ldots
$$

Also, Euler polynomials $E_{n}(t)$ can be defined as polynomials of degree $n \geq 0$ satisfying the conditions

$$
E_{m}^{\prime}(t)=m E_{m-1}(t), \quad m \geqslant 1 .
$$

By using Eq.(4), Eq.(5) or Eq.(6), the first Euler polynomials are described as

$$
\begin{gathered}
E_{0}(t)=1, \quad E_{1}(t)=t-\frac{1}{2}, \quad E_{2}(t)=t^{2}-t, \quad E_{3}(t)=t^{3}-\frac{3}{2} t^{2}+\frac{1}{4}, \quad E_{4}(t)=t^{4}-2 t^{3}+t, \\
E_{5}(t)=t^{5}-\frac{5}{2} t^{4}+\frac{5}{2} t^{2}-\frac{1}{2}, \quad E_{6}(t)=t^{6}-3 t^{5}+5 t^{3}-3 t, \quad E_{7}(t)=t^{7}-\frac{7}{2} t^{6}+\frac{35}{4} t^{4}-\frac{21}{2} t^{2}+\frac{17}{8},
\end{gathered}
$$

\section{Materials and Methods}

\subsection{Matrix Relations for Euler Polynomials}

The delay Volterra-Fredholm integro-differential equation in Eq.(1) is considered to create the matrices of each term. The desired solution $y(t)$ defined by the truncated Euler series Eq.(3) of Eq.(1) is modified to extract the matrix form, for $n=0,1,2, \ldots, N$ as

$$
y(t) \cong y_{N}(t)=\mathbf{E}(t) \mathbf{A}
$$

where

$$
\mathbf{E}(t)=\left[\begin{array}{llll}
E_{0}(t) & E_{1}(t) & \cdots & E_{N}(t)
\end{array}\right], \quad \mathbf{A}=\left[\begin{array}{llll}
a_{0} & a_{1} & \cdots & a_{N}
\end{array}\right]^{T}
$$


On the other hand, using Euler polynomials and Taylor expansion, and by means of Eq.(5), the matrix relation between standard base matrix and Euler base matrix is constructed as

$$
\mathbf{T}^{T}(t)=\left(\mathbf{S}^{-1}\right)^{T} \mathbf{E}^{T}(t) \Leftrightarrow \mathbf{T}(t)=\mathbf{E}(t)\left(\mathbf{S}^{-1}\right) \Rightarrow \mathbf{E}(t)=\mathbf{T}(t) \mathbf{S}
$$

where

$$
\begin{aligned}
& \mathbf{T}(t)=\left[1 t \cdots t^{N}\right], \\
& \left(\mathbf{S}^{-1}\right)^{T}=\left[\begin{array}{ccccc}
1 & 0 & 0 & \cdots & 0 \\
\frac{1}{2}\left(\begin{array}{c}
1 \\
0
\end{array}\right) & 1 & 0 & \cdots & 0 \\
\frac{1}{2}\left(\begin{array}{c}
2 \\
0
\end{array}\right) & \frac{1}{2}\left(\begin{array}{c}
2 \\
1
\end{array}\right) & 1 & \cdots & 0 \\
\vdots & \vdots & \vdots & \ddots & \vdots \\
\frac{1}{2}\left(\begin{array}{c}
N \\
0
\end{array}\right) & \frac{1}{2}\left(\begin{array}{c}
N \\
1
\end{array}\right) & \frac{1}{2}\left(\begin{array}{c}
N \\
2
\end{array}\right) & \cdots & 1
\end{array}\right]_{(N+1) \times(N+1)}
\end{aligned}
$$

The relation between the matrix $\mathbf{E}(t)$ and its derivatives are

$$
\mathbf{E}^{\prime}(t)=\mathbf{T}^{\prime}(t) \mathbf{S}=\mathbf{T}(t) \mathbf{B S}
$$

where

$$
\begin{gathered}
\mathbf{B}=\left[\begin{array}{ccccc}
0 & 1 & 0 & \cdots & 0 \\
0 & 0 & 2 & \cdots & 0 \\
\vdots & \vdots & \vdots & \ddots & \vdots \\
0 & 0 & 0 & 0 & N \\
0 & 0 & 0 & 0 & 0
\end{array}\right] \quad \mathbf{B}^{0}=\left[\begin{array}{ccccc}
1 & 0 & 0 & \cdots & 0 \\
0 & 1 & 0 & \cdots & 0 \\
\vdots & \vdots & \vdots & \ddots & \vdots \\
0 & 0 & 0 & \cdots & 0 \\
0 & 0 & 0 & \cdots & 1
\end{array}\right] \\
y^{(r)}(t)=\mathbf{E}^{(r)}(t) \mathbf{A}=\mathbf{T}(t) \mathbf{B}^{r} \mathbf{S A}, r=0,1,2, \ldots
\end{gathered}
$$

By putting $t \rightarrow \alpha_{r} t+\beta_{r}(t)$ in the relation (9), we obtain the matrix relation

$$
y^{(r)}\left(\alpha_{r} t+\beta_{r}(t)\right)=\mathbf{T}\left(\alpha_{r} t+\beta_{r}(t)\right) \mathbf{B}^{r} \mathbf{S} \mathbf{A}, \quad r=0,1,2, \ldots
$$

Note that the matrix $\mathbf{T}\left(\alpha_{r} t+\beta_{r}(t)\right)$ can be constituted as

$$
\begin{aligned}
& \mathbf{T}\left(\alpha_{r} t+\beta_{r}(t)\right)=\mathbf{T}(t) \mathbf{B}\left(\alpha_{r}, \beta_{r}(t)\right)
\end{aligned}
$$

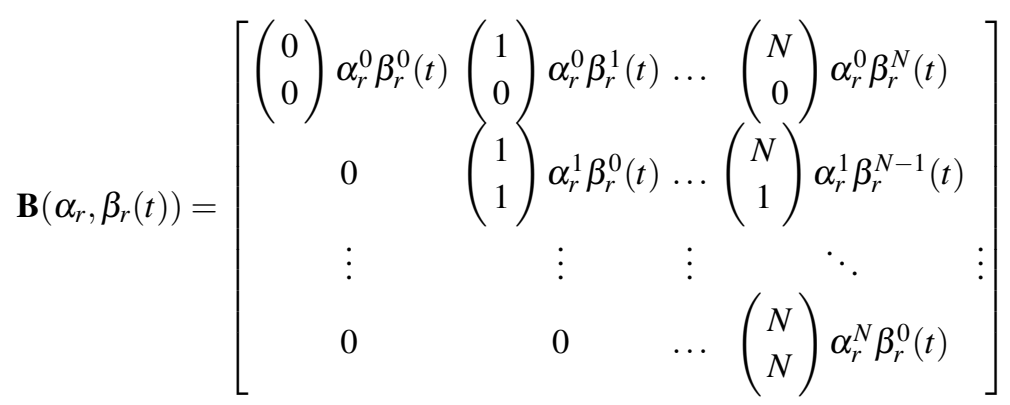


On the other hand, the matrix forms of $y^{(j)}\left(\tau_{j} s+\xi_{j}\right), y^{(p)}\left(\gamma_{p} s+\theta_{p}\right)$, the kernel functions $K_{j}^{f}(t, s)$ and $K_{p}^{v}(t, s)$ in Eq.(1) is computed as follows

$$
\begin{gathered}
y^{(j)}\left(\tau_{j} s+\xi_{j}\right)=\mathbf{T}\left(\tau_{j} s+\xi_{j}\right) \mathbf{B}^{j} \mathbf{S} \mathbf{A}, \quad j=0,1,2, \ldots \\
y^{(p)}\left(\gamma_{p} s+\theta_{p}\right)=\mathbf{T}\left(\gamma_{p} s+\theta_{p}\right) \mathbf{B}^{p} \mathbf{S A}, \quad p=0,1,2, \ldots \\
K_{j}^{f}(t, s)=\mathbf{T}(t) \mathbf{K}_{j}^{f} \mathbf{T}(s)^{T} \\
K_{p}^{v}(t, s)=\mathbf{T}(t) \mathbf{K}_{p}^{v} \mathbf{T}(s)^{T}
\end{gathered}
$$

where $\mathbf{K}_{j}^{f}=\mathbf{K}_{p}^{v}=\mathrm{K}=\left[k_{m n}\right], \quad m, n=0,1, \ldots, N$

$$
\begin{gathered}
k_{m n}=\frac{1}{m ! n !} \cdot \frac{\partial^{m+n} \mathrm{~K}(0,0)}{\partial t^{m} \partial s^{n}} \\
\int_{a}^{b} K_{j}^{f}(t, s) y^{(j)}\left(\tau_{j} s+\xi_{j}\right) d s=\mathbf{T}(t) \mathbf{K}_{j}^{f} \mathbf{Q}_{j}^{f}(t) \mathbf{B}\left(\tau_{j}, \xi_{j}\right) \mathbf{B}^{j} \mathbf{S} \mathbf{A} \\
\int_{u_{p}(t)}^{v_{p}(t)} K_{p}^{v}(t, s) y^{(p)}\left(\gamma_{p} s+\theta_{p}\right) d s=\mathbf{T}(t) \mathbf{K}_{p}^{v} \mathbf{Q}_{j}^{p}(t) \mathbf{B}\left(\gamma_{p}, \theta_{p}\right) \mathbf{B}^{p} \mathbf{S} \mathbf{A}
\end{gathered}
$$

where

$$
\left.\begin{array}{c}
\mathbf{Q}_{j}^{f}(t)=\left[q_{m n}^{f}(t)\right]=\int_{a}^{b} \mathrm{~T}^{T}(s) \mathrm{T}(s) d s, \\
\mathbf{Q}_{p}^{v}(t)=\left[q^{v}{ }_{m n}(t)\right]=\int_{u_{p}(t)}^{v_{p}(t)} \mathrm{T}^{T}(s) \mathrm{T}(s) d s, \\
q_{m n}^{f}(t)=\frac{b^{m+n+1}-a^{m+n+1}}{m+n+1} \\
q_{m n}^{v}(t)=\frac{v_{p}(t)^{m+n+1}-u_{p}(t)^{m+n+1}}{m+n+1}
\end{array}\right\} \quad m, n=0,1, \ldots, N
$$

By substituting the matrix relations Eq. (9), Eq. (10) and Eq. (14) into Eq.(1) and then by using the collocation points

$$
t_{i}=a+\frac{b-a}{N} i, \quad i=0,1, \ldots, N
$$

The system of matrix equations are obtained as follows:

$$
\begin{aligned}
\sum_{k=0}^{m} \mathbf{P}_{k}\left(t_{i}\right) \mathbf{T}\left(t_{i}\right) \mathbf{B}^{k} \mathbf{S A}+\sum_{r=0}^{m_{1}} \mathbf{Q}_{r}\left(t_{i}\right) \overline{\mathbf{T}}\left(t_{i}\right) \overline{\mathbf{B}}\left(\alpha_{r}, \beta_{r}\left(t_{i}\right)\right) \mathbf{B}^{r} \mathbf{S A}=g\left(t_{i}\right) & +\lambda_{1} \sum_{j=0}^{m_{2}} \mathbf{T}\left(t_{i}\right) \mathbf{K}_{j}^{f} \mathbf{Q}_{j}^{f}\left(t_{i}\right) \mathbf{B}\left(\tau_{j}, \xi_{j}\right) \mathbf{B}^{j} \mathbf{S A} \\
& +\lambda_{2} \sum_{p=0}^{m_{3}} \mathbf{T}\left(t_{i}\right) \mathbf{K}_{p}^{v} \mathbf{Q}_{j}^{p}\left(t_{i}\right) \mathbf{B}\left(\gamma_{p}, \theta_{p}\right) \mathbf{B}^{p} \mathbf{S A}
\end{aligned}
$$

$$
\sum_{k=0}^{m} \mathbf{P}_{k} \mathbf{T} \mathbf{B}^{k} \mathbf{S A}+\sum_{r=0}^{m_{1}} \mathbf{Q}_{r} \overline{\mathbf{T B}}\left(\alpha_{r}, \beta_{r}\right) \mathbf{B}^{r} \mathbf{S A}=\mathbf{G}+\lambda_{1} \sum_{j=0}^{m_{2}} \mathbf{T} \mathbf{K}_{j}^{f} \mathbf{Q}_{j}^{f} \mathbf{B}\left(\tau_{j}, \xi_{j}\right) \mathbf{B}^{j} \mathbf{S A}+\lambda_{2} \sum_{p=0}^{m_{3}} \overline{\mathbf{T}} \overline{\mathbf{K}_{p}^{v}} \overline{\mathbf{Q}_{p}^{v}} \mathbf{B}\left(\gamma_{p}, \theta_{p}\right) \mathbf{B}^{p} \mathbf{S A}
$$


where

$$
\begin{gathered}
\mathbf{P}_{k}=\left[\begin{array}{ccc}
P_{k}\left(t_{0}\right) & \cdots & 0 \\
\vdots & \ddots & \vdots \\
0 & \cdots & P_{k}\left(t_{N}\right)
\end{array}\right], \quad \mathbf{T}=\left[\begin{array}{c}
\mathrm{T}\left(t_{0}\right) \\
\mathrm{T}\left(t_{1}\right) \\
\vdots \\
\mathrm{T}\left(t_{N}\right)
\end{array}\right], \\
\mathbf{Q}_{r}=\left[\begin{array}{ccc}
Q_{r}\left(t_{0}\right) & \cdots & 0 \\
\vdots & \ddots & \vdots \\
0 & \cdots & Q_{r}\left(t_{N}\right)
\end{array}\right], \quad \overline{\mathbf{T}}=\left[\begin{array}{ccc}
T\left(t_{0}\right) & \cdots & 0 \\
\vdots & \ddots & \vdots \\
0 & \cdots & T\left(t_{N}\right)
\end{array}\right], \\
\mathbf{G}=\left[\begin{array}{c}
g\left(t_{0}\right) \\
g\left(t_{1}\right) \\
\vdots \\
g\left(t_{N}\right)
\end{array}\right], \quad \overline{\mathbf{K}}=\left[\begin{array}{cccc}
\mathrm{K} & 0 & \cdots & 0 \\
0 & \mathrm{~K} & 0 & \vdots \\
\vdots & \cdots & \ddots & 0 \\
0 & \cdots & 0 & \mathrm{~K}
\end{array}\right], \quad \overline{\mathbf{Q}}(t)=\left[\begin{array}{c}
\mathrm{Q}\left(t_{0}\right) \\
\mathrm{Q}\left(t_{1}\right) \\
\vdots \\
\mathrm{Q}\left(t_{N}\right)
\end{array}\right],
\end{gathered}
$$

or briefly

$$
\mathbf{W A}=\mathbf{G} \quad \Leftrightarrow \quad[\mathbf{W}: \mathbf{G}]
$$

where

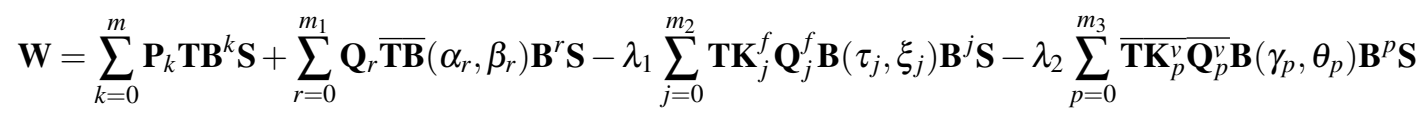

Besides, we can find for the condition Eq.(2), by using the relation Eq.(9),

$$
\sum_{k=0}^{m-1}\left(a_{j k} \mathbf{T}(a) \mathbf{B}^{k} \mathbf{S}+b_{j k} \mathbf{T}(b) \mathbf{B}^{k} \mathbf{S}\right) \mathbf{A}=\left[\mu_{j}\right] \quad \text { or } \quad[\mathbf{U}: \mathbf{A}]
$$

where

$$
\mathbf{U}=\left[\begin{array}{cccc}
u_{00} & u_{01} & \cdots & u_{0 N} \\
u_{10} & u_{11} & \cdots & u_{1 N} \\
\vdots & \cdots & \ddots & \vdots \\
u_{(r-1) 0} & \cdots & \cdots & u_{(r-1) N}
\end{array}\right]
$$

Consequently, any one row of Eq.(16) by the row matrix Eq.(17) is replaced, hence the desired augmented matrix or the resulted matrix equation comes out as

$$
\widetilde{\mathbf{W}} \mathbf{A}=\widetilde{\mathbf{G}} \Rightarrow[\widetilde{\mathbf{W}}: \widetilde{\mathbf{G}}]
$$

which suits to the system of linear algebraic equations with the Euler coefficients $a_{n}$. The solution of this system provides the matrix $\mathbf{A}$ and the solution of Eq.(1) - Eq.(2) is

$$
y_{N}(t)=\mathbf{E}(t) \mathbf{A}=\mathbf{T}(t) \mathbf{S A}
$$




\subsection{Residual Error Analysis}

We define the residual function using the linear part of Eq.(1) for the present method as $[9,10,11,12]$

$$
R_{N}(t)=L\left[y_{N}(t)\right]-g(t)
$$

By means of the residual function defined by $R_{N}(t)$ and the mean value of the function $\left|R_{N}(t)\right|$ on the interval $[a, b]$, the accuracy of the solution can be controlled and the error can be estimated $[6,7,10,11]$. Thus, we can estimate the upper bound of the mean error $\overline{R_{N}}$ as follows:

$$
\begin{gathered}
\left|\int_{a}^{b} R_{N}(t) d t\right| \leqslant \int_{a}^{b}\left|R_{N}(t) d t\right| \\
\int_{a}^{b}\left|R_{N}(t)\right| d t=(b-a)\left|R_{N}(c)\right|, a \leqslant c \leqslant b \\
\Rightarrow\left|\int_{a}^{b} R_{N}(t) d t\right|=(b-a)\left|R_{N}(c)\right| \\
\Rightarrow(b-a)\left|R_{N}(c)\right| \leqslant \int_{a}^{b}\left|R_{N}(t)\right| d t \\
\left|R_{N}(c)\right| \leqslant \frac{\int_{a}^{b}\left|R_{N}(t)\right| d t}{b-a}=\overline{R_{N}}
\end{gathered}
$$

Kürkçü and Coworkers developed the convergence of Dickson polynomial solution of the nonlinear model problem using the residual function in Banach space [9]. We reveal the following convergence criteria for Euler polynomial solutions.

\section{Numerical Examples}

In this section, some numerical examples of the problem Eq.(1) are given to illustrate the accuracy and effectiveness properties of the method.

Example 3.1. Let us first consider the fourth order Fredholm integro differential equation with delay term [13,14]

$$
y^{(4)}(t)-y^{\prime \prime}(t-1)+t y(t+0.5)=g(t)+\int_{0}^{1}\left[t \cos (s) y^{\prime}(s+1)+t \sin (s) y^{\prime \prime}(s-0.5)\right] d s
$$

with the initial conditions $y(0)=0, y^{\prime}(0)=1, y^{\prime \prime}(0)=0, y^{(3)}(0)=-1$ Here,

$$
\begin{aligned}
g(t)=\sin (t)+\sin (t-1)+t \sin (t+0.5)+0.25 t \sin (1) & -0.5 t \cos (1)-0.25 t \sin (3)-0.25 t \sin (0.5) \\
& +0.5 t \cos (0.5)-0.25 t \sin (1.5)
\end{aligned}
$$

We note that the exact solution of the problem is $y(t)=\sin (t)$. Following the procedure in Section 2, we find the solution of our problem for different values of $\mathrm{N}$ as follows:

$$
\begin{gathered}
y_{5}(t)=0.00657 t^{5}+0.00225 t^{4}-0.16667 t^{3}+t \\
y_{8}(t)=9.41179 * 10^{-6} t^{8}-0.0002 t^{7}-0.00009 t^{6}+0.00868 t^{5}-0.00075 t^{4}-0.16667 t^{3}+t
\end{gathered}
$$


The absolute errors of this example are tabulated for $N=5,8$ in Table 1 . And also, the absolute errors obtained by our method are compared with the absolute errors of Müntz-Legendre polynomials given in [13] and Galerkin method given in [14]. As can be seen from the tables, the result obtained by the present method is almost the same as the results of the exact solution. The present method is also effective and convenient. The absolute errors in the numerical solution of Example 3.1 are seen in Fig. 1. The error decreases when the integer $\mathrm{N}$ is increased.

Table 1: Comparisons of the absolute errors for $\mathrm{N}=5,8$ in Example 3.1.

\begin{tabular}{|c|c|c|c|c|c|c|}
\hline $\mathrm{t}$ & $\begin{array}{c}\text { Present } \\
\text { method } \\
\left|e_{5}(t)\right|\end{array}$ & $\begin{array}{c}\text { Present } \\
\text { method } \\
\left|e_{8}(t)\right|\end{array}$ & $\begin{array}{c}\text { Müntz } \\
\text { Legendre } \\
\left|e_{5}(t)\right|\end{array}$ & $\begin{array}{c}\text { Müntz } \\
\text { Legendre } \\
\left|e_{8}(t)\right|\end{array}$ & $\begin{array}{c}\text { Galerkin } \\
\text { method } \\
\left|e_{5}(t)\right|\end{array}$ & $\begin{array}{c}\text { Galerkin } \\
\text { method } \\
\left|e_{8}(t)\right|\end{array}$ \\
\hline 0.2 & $3.047 \mathrm{E}-06$ & $1.102 \mathrm{E}-06$ & $1.202 \mathrm{E}-05$ & $9.251 \mathrm{E}-07$ & $3.386 \mathrm{E}-06$ & $3.407 \mathrm{E}-06$ \\
\hline 0.4 & $4.003 \mathrm{E}-05$ & $1.616 \mathrm{E}-05$ & $1.681 \mathrm{E}-04$ & $1.901 \mathrm{E}-05$ & $5.474 \mathrm{E}-05$ & $5.239 \mathrm{E}-05$ \\
\hline 0.6 & $1.609 \mathrm{E}-04$ & $7.530 \mathrm{E}-05$ & $7.266 \mathrm{E}-04$ & $1.194 \mathrm{E}-04$ & $2.824 \mathrm{E}-04$ & $2.587 \mathrm{E}-04$ \\
\hline 0.8 & $3.882 \mathrm{E}-04$ & $2.200 \mathrm{E}-04$ & $1.891 \mathrm{E}-03$ & $4.545 \mathrm{E}-04$ & $9.209 \mathrm{E}-04$ & $8.003 \mathrm{E}-04$ \\
\hline 1 & $6.907 \mathrm{E}-04$ & $4.991 \mathrm{E}-04$ & $3.589 \mathrm{E}-03$ & $1.304 \mathrm{E}-03$ & $2.354 \mathrm{E}-03$ & $1.937 \mathrm{E}-03$ \\
\hline
\end{tabular}

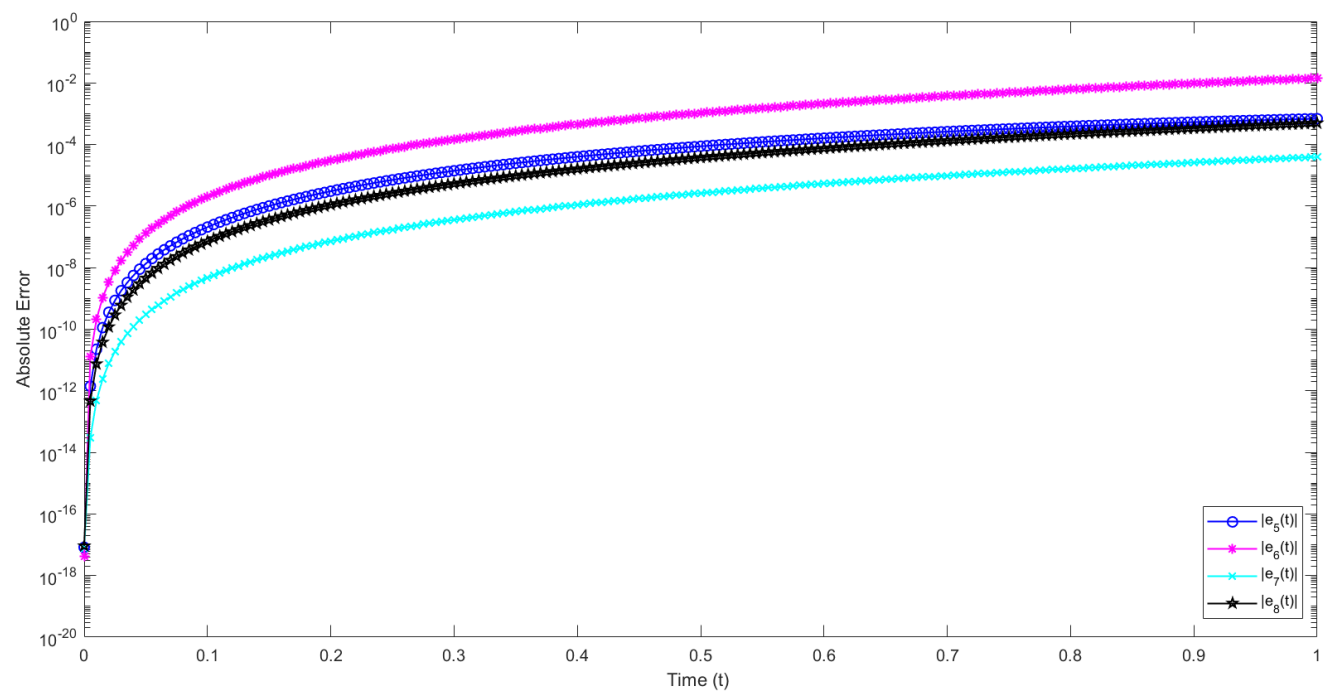

Fig. 1: The absolute errors of Example 3.1 for $5 \leq N \leq 8$.

As can be seen from Figure (1), it has been observed that the odd values of $\mathrm{N}$ are closer to the exact solution.

The upper error bounds are obtained as

$$
\begin{gathered}
\left|\overline{R_{5}}\right|=0.028599, \quad\left|\overline{R_{6}}\right|=0.063191, \\
\left|\overline{R_{7}}\right|=0.000801, \quad\left|\overline{R_{8}}\right|=9.956 e-05,
\end{gathered}
$$


By using the Theorem in [9],

$$
\mu_{N}=\left\{\frac{\left|\overline{R_{6}}\right|}{\left|\overline{R_{5}}\right|}, \frac{\left|\overline{R_{7}}\right|}{\left|\overline{R_{6}}\right|}, \frac{\left|\overline{R_{8}}\right|}{\left|\overline{R_{7}}\right|}, \ldots\right\}=\{2.209531,0.012672,0.12433, \ldots\}
$$

so,

$$
\frac{\left|\overline{R_{N+1}}\right|}{\left|\overline{R_{N}}\right|}<1
$$

The first four values of the residual error function are shown in Fig. 2. It can be concluded that, the residual error decreases as $\mathrm{N}$ values are increasing.

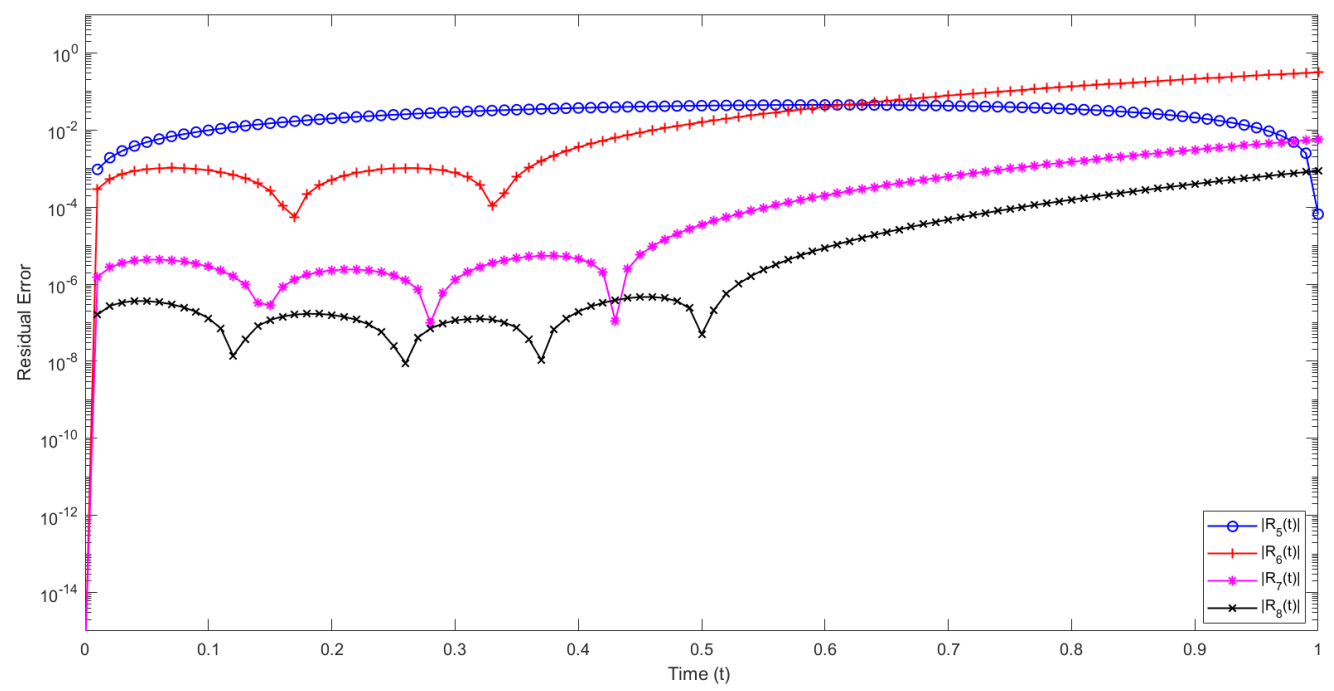

Fig. 2: The residual errors of Example 3.1 for $5 \leq N \leq 8$.

Example 3.2. Let us consider the second order Volterra integro differential equation with delay term $[14,15,16]$

$$
y^{\prime \prime}(t)-\frac{3}{4} y(t)+y\left(\frac{t}{2}\right)=-\frac{11}{4} \sin t+\sin \left(\frac{t}{2}\right)+t \cos t+\int_{0}^{t} t y(s) d s
$$

with the initial condition $y(0)=0, y^{\prime}(0)=1$.

Following the procedure in Section2, we find the solution of our problem for different values of $\mathrm{N}$ as follows:

$$
\begin{gathered}
y_{4}(t)=0.01026 t^{4}-0.17007 t^{3}+t \\
y_{5}(t)=0.00792 t^{5}+0.00033 t^{4}-0.16675 t^{3}+t \\
y_{6}(t)=-0.00045 t^{6}+0.00872 t^{5}-0.00015 t^{4}-0.16664 t^{3}+t \\
y_{7}(t)=-0.00019 t^{7}-0.00002 t^{6}+0.00835 t^{5}-3.85053 * 10^{-6} t^{4}-0.16667 t^{3}+t \\
y_{8}(t)=9.04859 * 10^{-6} t^{8}-0.00021 t^{7}+9.04145 * 10^{-6} t^{6}+0.00833 t^{5}+8.40882 * 10^{-7} t^{4}-0.16667 t^{3}+t
\end{gathered}
$$


The numerical results of this example are tabulated for $4 \leq N \leq 8$ in Table 2 . In addition, the absolute errors obtained by our method are compared with the results of Taylor method given in [15], Laguerre method given in [16] and Galerkin method given in [14] and tabulated in Table 3. As can be seen from the tables, the result obtained by the present method is almost the same as the results of the exact solution. The present method is also effective and convenient. The absolute errors in the numerical solution of Example 3.2 are seen in Fig. 3. The error decreases when the integer $\mathrm{N}$ is increased.

Table 2: Comparisons of numerical results for $4 \leq N \leq 8$ in Example 3.2.

\begin{tabular}{|c|c|c|c|c|c|c|}
\hline $\mathrm{t}$ & $\sin t$ & $y_{4}(t)$ & $y_{5}(t)$ & $y_{6}(t)$ & $y_{7}(t)$ & $y_{8}(t)$ \\
\hline 0.2 & 0.1986693308 & 0.1986558233 & 0.1986690957 & 0.1986693798 & 0.1986693315 & 0.1986693307 \\
\hline 0.4 & 0.3894183423 & 0.3893779227 & 0.3894178144 & 0.3894184466 & 0.3894183439 & 0.3894183421 \\
\hline 0.6 & 0.5646424734 & 0.5645937486 & 0.5646415410 & 0.5646426458 & 0.5646424758 & 0.5646424731 \\
\hline 0.8 & 0.7173560909 & 0.7171247598 & 0.7173566510 & 0.7173563956 & 0.7173560941 & 0.7173560905 \\
\hline 1 & 0.8414709848 & 0.8401864237 & 0.8415046851 & 0.8414760090 & 0.8414708784 & 0.8414709736 \\
\hline
\end{tabular}

Table 3: Comparisons of the absolute errors for $\mathrm{N}=7,8$ in Example 3.2.

\begin{tabular}{|c|c|c|c|c|c|c|c|}
\hline $\mathrm{t}$ & $\begin{array}{c}\text { Euler } \\
e_{7}(t)\end{array}$ & $\begin{array}{c}\text { Euler } \\
e_{8}(t)\end{array}$ & $\begin{array}{c}\text { Galerkin } \\
e_{7}(t)\end{array}$ & $\begin{array}{c}\text { Galerkin } \\
e_{8}(t)\end{array}$ & $\begin{array}{c}\text { Taylor } \\
e_{7}(t)\end{array}$ & $\begin{array}{c}\text { Taylor } \\
e_{10}(t)\end{array}$ & $\begin{array}{c}\text { Laguerre } \\
e_{10}(t)\end{array}$ \\
\hline 0.2 & $7.301 \mathrm{E}-10$ & $9.104 \mathrm{E}-11$ & $6.402 \mathrm{E}-10$ & $4.941 \mathrm{E}-11$ & $2.35 \mathrm{E}-07$ & $7.00 \mathrm{E}-10$ & $2.346 \mathrm{E}-10$ \\
\hline 0.4 & $1.546 \mathrm{E}-09$ & $1.963 \mathrm{E}-10$ & $3.366 \mathrm{E}-10$ & $6.526 \mathrm{E}-11$ & $5.27 \mathrm{E}-07$ & $1.50 \mathrm{E}-09$ & $5.137 \mathrm{E}-09$ \\
\hline 0.6 & $2.372 \mathrm{E}-09$ & $3.047 \mathrm{E}-10$ & $4.694 \mathrm{E}-10$ & $6.589 \mathrm{E}-11$ & $9.32 \mathrm{E}-07$ & $2.40 \mathrm{E}-09$ & $8.339 \mathrm{E}-09$ \\
\hline 0.8 & $3.201 \mathrm{E}-09$ & $3.945 \mathrm{E}-10$ & $7.173 \mathrm{E}-10$ & $3.531 \mathrm{E}-11$ & $5.60 \mathrm{E}-07$ & $3, .00 \mathrm{E}-09$ & $1.152 \mathrm{E}-08$ \\
\hline 1 & $1.064 \mathrm{E}-07$ & $1.119 \mathrm{E}-08$ & $3.819 \mathrm{E}-11$ & $6.221 \mathrm{E}-11$ & $3.37 \mathrm{E}-05$ & $1.06 \mathrm{E}-07$ & $3.640 \mathrm{E}-09$ \\
\hline
\end{tabular}

The upper error bounds are obtained as

$$
\begin{gathered}
\left|\overline{R_{4}}\right|=0.009365, \quad\left|\overline{R_{5}}\right|=0.000382, \quad\left|\overline{R_{6}}\right|=6.357 e-05, \\
\left|\overline{R_{7}}\right|=1.838 e-06, \quad\left|\overline{R_{8}}\right|=2.079 e-07,
\end{gathered}
$$

By using the Theorem in [9],

$$
\mu_{N}=\left\{\frac{\left|\overline{R_{5}}\right|}{\left|\overline{R_{4}}\right|}, \frac{\left|\overline{R_{6}}\right|}{\left|\overline{R_{5}}\right|}, \frac{\left|\overline{R_{7}}\right|}{\left|\overline{R_{6}}\right|}, \ldots\right\}=\{0.040748,0.166583,0.028917, \ldots\}
$$

so,

$$
\frac{\left|\overline{R_{N+1}}\right|}{\left|\overline{R_{N}}\right|}<1
$$

The first five values of the residual error function are shown in Fig. 4. It can be concluded that, the residual error decreases as $\mathrm{N}$ values are increasing. 


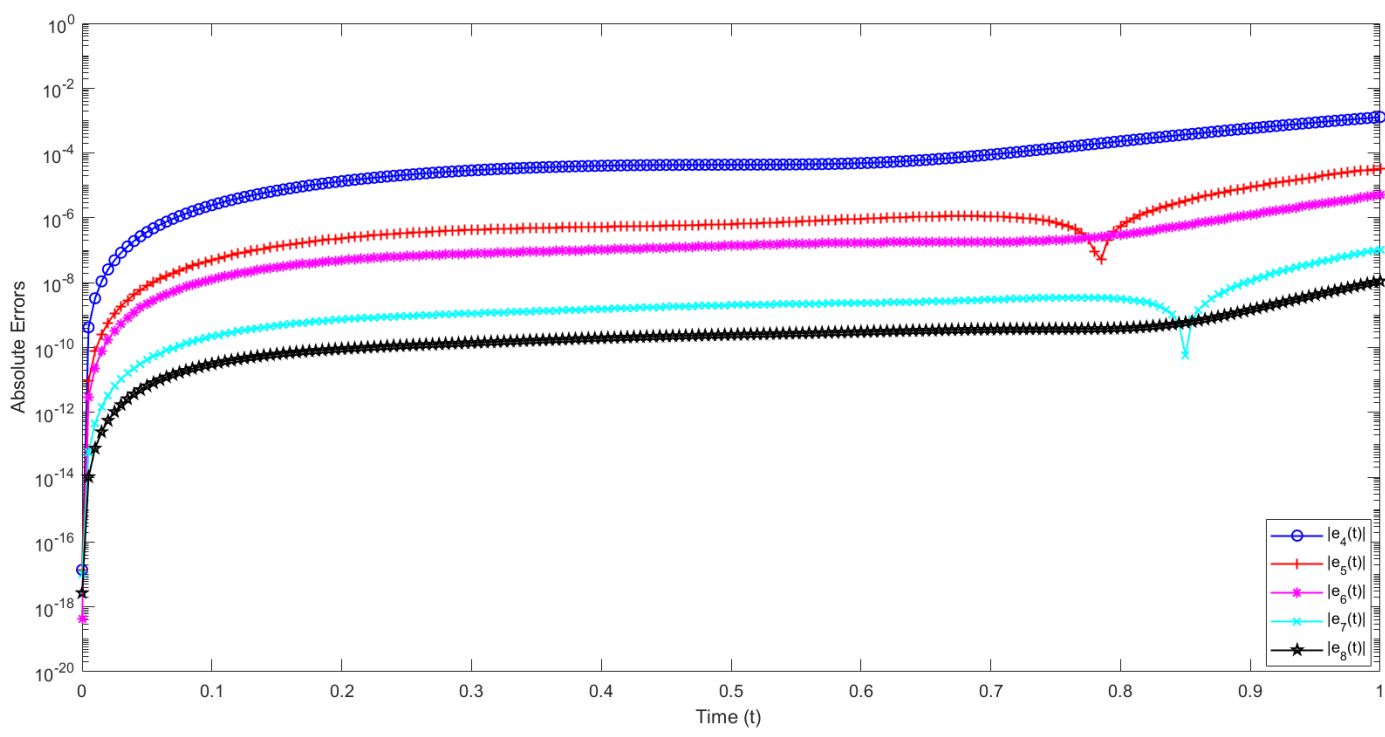

Fig. 3: Absolute errors of Example 3.2 for $4 \leq N \leq 8$.

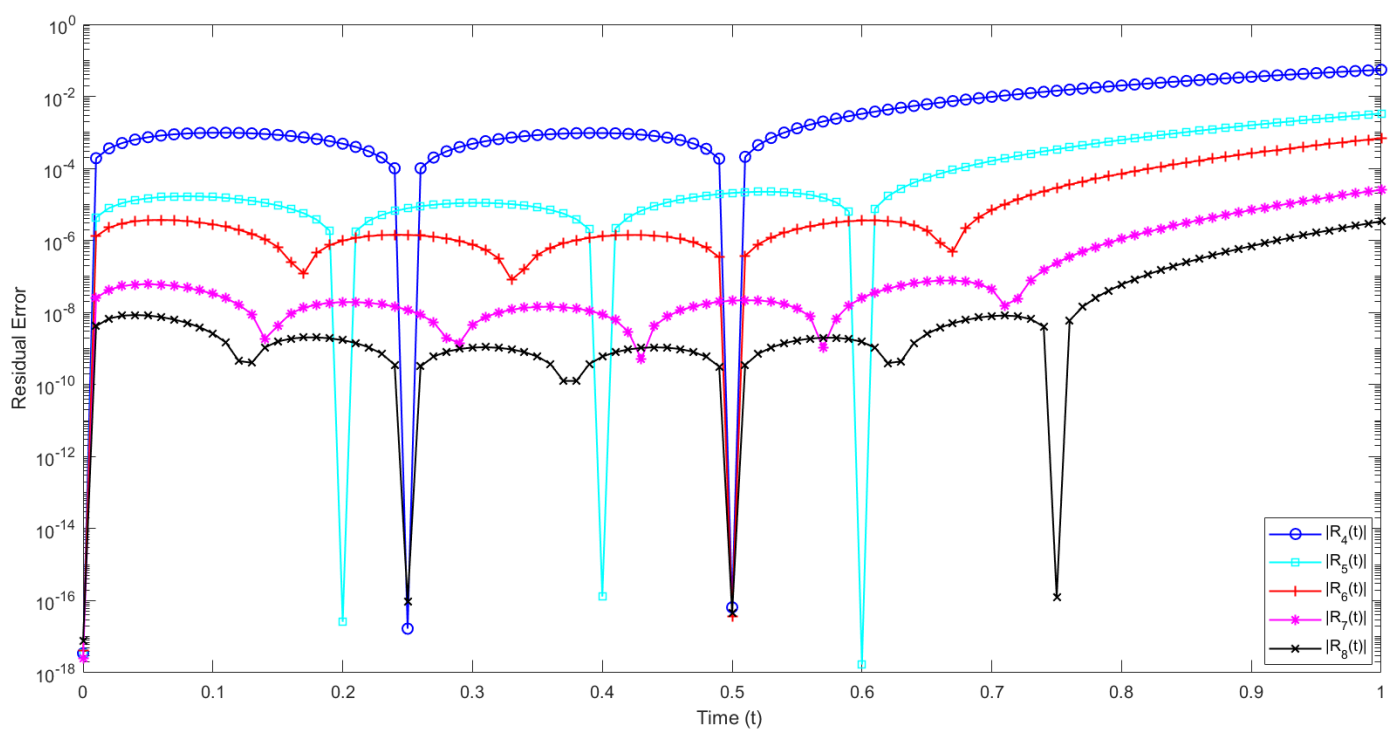

Fig. 4: The residual errors of Example 3.2 for $4 \leq N \leq 8$.

Example 3.3. Let us consider the second order Volterra-Fredholm integro differential equation with delay term $[14,17]$

$$
\left(t^{2}+1\right) y^{\prime \prime}(0.2 t)+t y^{\prime}(t-1)-(t-1) y(t+2)+y(t)=g(t)+2 \int_{0}^{1} t y^{\prime}(s) d s+\int_{0}^{\frac{t}{2}+1}\left(t s^{2}+s t^{2}\right) y^{\prime \prime}(s) d s
$$


with the conditions $y(0)=-1$ and $y^{\prime}(1)=3$. Here $g(t)=6-\frac{14 t}{3}-t^{2}-\frac{5 t^{3}}{2}-\frac{t^{4}}{3}+2$. We have the solution for $N=2$,

$$
y_{2}(t)=t^{2}+t-1
$$

which is the exact solution. In a similar way, the same solution is obtained for $N \geq 2$.

Example 3.4. Our last example first order Volterra integro differential equation with delay term $[14,17,18]$

$$
y^{\prime}(t)+2 y^{\prime}(t-0.5)-y(t)+\left(t^{2}-t\right) y(0.5 t-1)=g(t)+\int_{0}^{t} t e^{-s} y(s) d s+\int_{0}^{\frac{t}{2}}\left(t^{2}-2 s-2\right) y^{\prime}(s) d s
$$

with the condition $y(0)=1$. Here $g(t)=\left(t^{2}-t\right) e^{0.5 t-1}+2 e^{t-0.5}-t^{2} e^{0.5 t}+t e^{0.5 t}$.

We note that the exact solution of the problem is $y(t)=e^{t}$. Solutions of our problem for different values of $\mathrm{N}$ as follows:

$$
\begin{gathered}
y_{4}(t)=0.06016 t^{4}+0.164606 t^{3}+0.494345 t^{2}+1.000633 t+1 \\
y_{7}(t)=0.00025 t^{7}+0.00140 t^{6}+0.00830 t^{5}+0.04164 t^{4}+0.16668 t^{3}+0.50001 t^{2}+t+1
\end{gathered}
$$

The absolute errors of this example are tabulated for $N=4$ and $N=7$ in Table 4 and 5. And also, the results obtained by our method are compared with the results of Chelyskov collocation method given in [18], Dickson collocation method given in [17] and Galerkin method given in [14]. As can be seen from the tables, the result obtained by the present method is almost the same as the results of the exact solution. The present method is also very effective and convenient. The absolute errors in the numerical solution of Example 3.4 are seen in Fig. 5. The error decreases when the integer $\mathrm{N}$ is increased.

Table 4: Comparisons of the absolute errors for $\mathrm{N}=4$ in Example 3.4.

\begin{tabular}{|c|c|c|c|c|}
\hline $\mathbf{t}$ & $\begin{array}{c}\text { Euler } \\
\left|e_{4}\left(t_{i}\right)\right|\end{array}$ & $\begin{array}{c}\text { Chelyskov } \\
\left|e_{4}\left(t_{i}\right)\right|\end{array}$ & $\begin{array}{c}\text { Dickson } \\
\left|e_{4}\left(t_{i}\right)\right|\end{array}$ & $\begin{array}{c}\text { Galerkin } \\
\left|e_{4}\left(t_{i}\right)\right|\end{array}$ \\
\hline 0.2 & $8.925 \mathrm{E}-05$ & $2.926 \mathrm{E}-04$ & $1.738 \mathrm{E}-04$ & $2.619 \mathrm{E}-04$ \\
\hline 0.4 & $4.015 \mathrm{E}-04$ & $2.704 \mathrm{E}-04$ & $5.303 \mathrm{E}-04$ & $4.195 \mathrm{E}-04$ \\
\hline 0.6 & $4.235 \mathrm{E}-04$ & $4.497 \mathrm{E}-04$ & $4.756 \mathrm{E}-04$ & $9.470 \mathrm{E}-05$ \\
\hline 0.8 & $2.648 \mathrm{E}-04$ & $1.740 \mathrm{E}-03$ & $8.732 \mathrm{E}-04$ & $6.680 \mathrm{E}-04$ \\
\hline 1 & $1.458 \mathrm{E}-03$ & $2.432 \mathrm{E}-03$ & $5.833 \mathrm{E}-04$ & $8.687 \mathrm{E}-04$ \\
\hline
\end{tabular}

The upper error bounds are obtained as

$$
\left|\overline{R_{4}}\right|=0.00068, \quad\left|\overline{R_{5}}\right|=7.808 e-06, \quad\left|\overline{R_{6}}\right|=1.161 e-06, \quad\left|\overline{R_{7}}\right|=4.047 e-07,
$$

By using the Theorem in [9],

$$
\mu_{N}=\left\{\frac{\left|\overline{R_{5}}\right|}{\left|\overline{R_{4}}\right|}, \frac{\left|\overline{R_{6}}\right|}{\left|\overline{R_{5}}\right|}, \frac{\left|\overline{R_{7}}\right|}{\left|\overline{R_{6}}\right|}, \ldots\right\}=\{0.011477,0.148705,0.348547, \ldots\}
$$


Table 5: Comparisons of the absolute errors for $\mathrm{N}=7$ in Example 3.4.

\begin{tabular}{|c|c|c|c|c|}
\hline $\mathbf{t}$ & $\begin{array}{c}\text { Euler } \\
\left|e_{7}\left(t_{i}\right)\right|\end{array}$ & $\begin{array}{c}\text { Chelyskov } \\
\left|e_{7}\left(t_{i}\right)\right|\end{array}$ & $\begin{array}{c}\text { Dickson } \\
\left|e_{7}\left(t_{i}\right)\right|\end{array}$ & $\begin{array}{c}\text { Galerkin } \\
\left|e_{7}\left(t_{i}\right)\right|\end{array}$ \\
\hline 0.2 & $3.397 \mathrm{E}-07$ & $7.378 \mathrm{E}-06$ & $7.414 \mathrm{E}-07$ & $5.775 \mathrm{E}-07$ \\
\hline 0.4 & $1.240 \mathrm{E}-06$ & $1.773 \mathrm{E}-06$ & $1.355 \mathrm{E}-06$ & $1.746 \mathrm{E}-06$ \\
\hline 0.6 & $1.331 \mathrm{E}-06$ & $1.851 \mathrm{E}-05$ & $4.143 \mathrm{E}-07$ & $1.685 \mathrm{E}-06$ \\
\hline 0.8 & $4.252 \mathrm{E}-07$ & $2.969 \mathrm{E}-05$ & $1.903 \mathrm{E}-06$ & $7.401 \mathrm{E}-07$ \\
\hline 1 & $3.067 \mathrm{E}-06$ & $2.117 \mathrm{E}-06$ & $3.347 \mathrm{E}-06$ & $3.357 \mathrm{E}-06$ \\
\hline
\end{tabular}

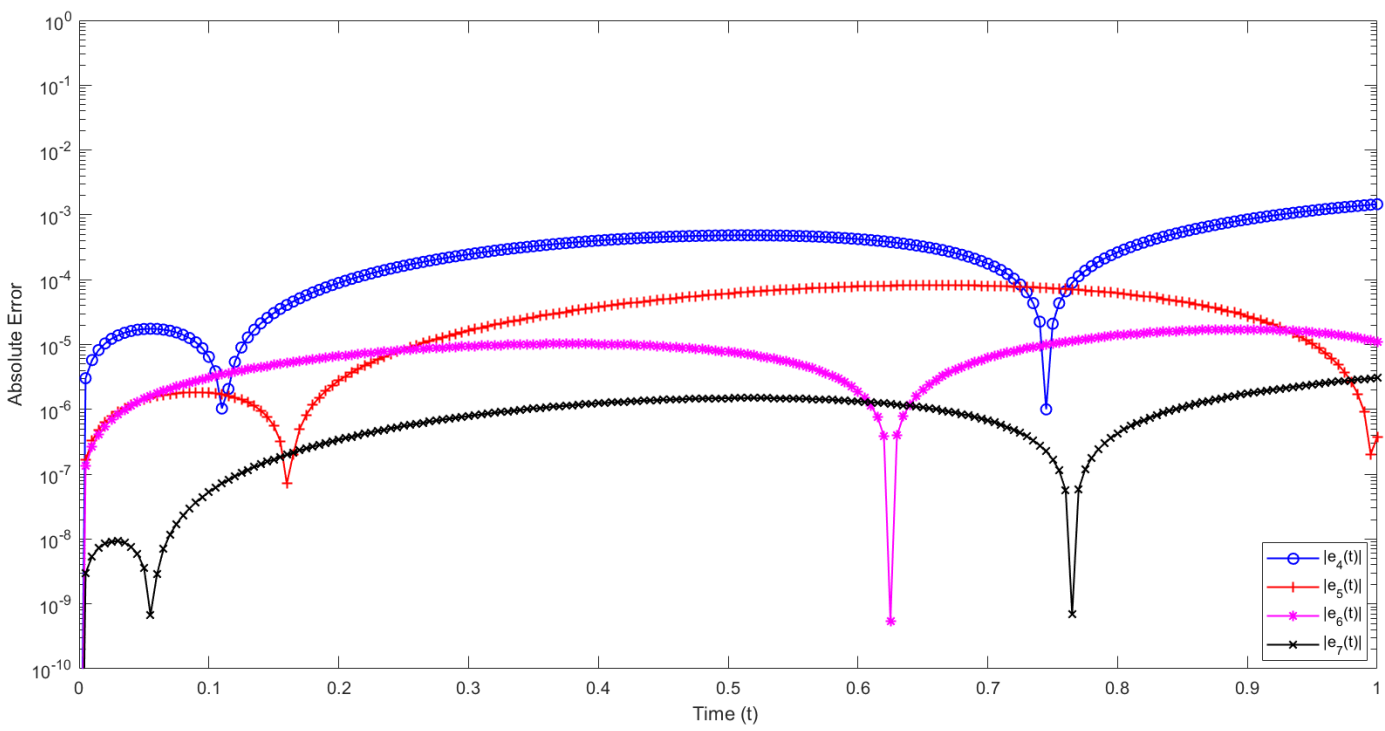

Fig. 5: Absolute errors of Example 3.4 for $4 \leq N \leq 7$.

so,

$$
\frac{\left|\overline{R_{N+1}}\right|}{\left|\overline{R_{N}}\right|}<1
$$

The first four values of the residual error function are shown in Fig. 6. It can be concluded that, the residual error decreases as $\mathrm{N}$ values are increasing.

\section{Conclusion}

In this paper, we presented the Euler collocation scheme of the linear delay integro-differential equations. In addition, we constructed an error problem by means of the residual error function and this problem is solved by Euler collocation scheme. One can see that the results of the Euler matrix method have better accuracy than those generated by some other numerical methods. Hence, it is an effective and convenient approach to solve the indicated problems, producing approximate and exact solutions. 


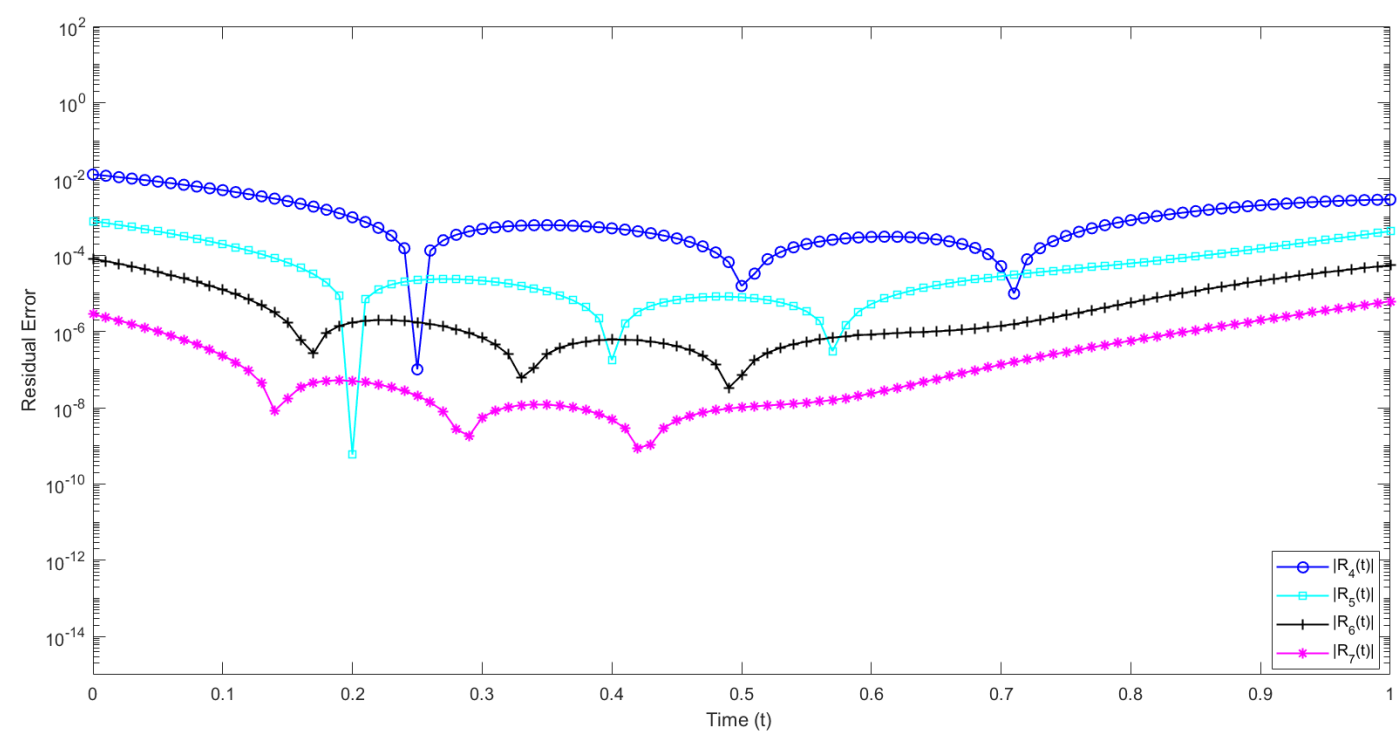

Fig. 6: The residual errors of Example 3.4 for $4 \leq N \leq 7$.

\section{Acknowledgements}

The authors would like to acknowledge to TUBITAK for their financial support with 2211/A National PhD Scholarship Program.

\section{Competing interests}

The authors declare that they have no competing interests.

\section{Authors' contributions}

All authors have contributed to all parts of the article. All authors read and approved the final manuscript.

\section{References}

[1] Sadri K., Amini A., Cheng C., A new numerical method for delay and advanced integro-differential equations, Numerical Algorithms, 77, 381?412, doi.org/10.1007/s11075-017-0320-2, (2018).

[2] Volterra V., Theory of Functionals and of Integral and Integro-Differential Equations, Dover Publications, (2005).

[3] Brunner H., Recent advances in the numerical analysis of volterra functional differential equations with variable delays, Journal of Computational and Applied Mathematics, 228, 524-537, doi:10.1016/j.cam.2008.03.024, (2009).

[4] Yüzbaşı Ş., Karaçayır M., A Numerical Approach for Solving High-Order Linear Delay Volterra Integro-Differential Equations, , International Journal of Computational Methods, 15, 05, doi.org/10.1142/S0219876218500421, (2018).

[5] Mirzaee, F., Bimes, L., Tohidi,E., A numerical framework for solving high order pantograph delay Volterra integro-differential equations, Kuwait J. Sci. 43(1), 69-83, (2016).

[6] Balc1 M.A., Sezer M., Hybrid Euler-Taylor matrix method for solving of generalized linear Fredholm integro-differential difference equations, Applied Mathematics and Computation, vol. 273, 33?41, doi:10.1016/j.amc.2015.09.085, (2016). 
[7] Baykuş Savaşaneril N., Sezer M., Hybrid Taylor-Lucas Collocation Method for Numerical Solution of High-Order Pantograph Type Delay Differential Equations with Variables Delays, Appl. Math. Inf. Sci. 11, No. 6, 1795-1801, doi:10.18576/amis/110627, (2017).

[8] Cheon G.S., A note on the Bernoulli and Euler polynomials, Applied Mathematics Letters, 16, 365-368, doi:10.1016/S08939659(03)80058-7, (2003).

[9] Kürkçü Ö.K., Aslan E., Sezer M., A numerical method for solving some model problems arising in science and convergence analysis based on residual function, Applied Numerical Mathematics, 121, 134?148, doi:10.1016/j.apnum.2017.06.015, (2017).

[10] Kürkçü Ö.K., Aslan E., Sezer M., İlhan, Ö., A numerical approach technique for solving generalized delay integrodifferential equations with functional bounds by means of Dickson polynomials, Int. J. Comput. Methods, 15(5), No: 1850039, doi.org/10.1142/S0219876218500391, (2018).

[11] Yüzbaş1 Ş., Sezer M., Shifted Legendre approximation with the residual correction to solve pantograph-delay type differential equations, Appl. Math. Model., 39, 6529-6542, doi.org/10.1016/j.apm.2015.02.006, (2015).

[12] İbiş, B., Bayram M., A new collocation method based on Euler polynomials for solution of generalized pantograph equations, Biska, New Trends in Mathematical Sciences, 4, No. 4, 285-294, dx.doi.org/10.20852/ntmsci.2016.115, (2016).

[13] Yüzbaşı Ş., Gök E., Sezer M., Müntz-Legendre polynomial solutions of linear delay Fredholm integro-differential equations and residual correction, Mathematical and Computational Applications, Vol. 18, No. 3, pp. 476-485, (2013).

[14] Karaçayır M., Diferansiyel, fonksiyonel diferansiyel ve integro-diferansiyel denklemler ve sistemleri için Galerkin-tipi bir sayisal yöntem, Phd thesis, Akdeniz University, Antalya, (2018).

[15] Gülsu M., Sezer M., A Collocation Approach for the Numerical Solution of Certain Linear Retarded and Advanced Integrodifferential Equations with Linear Functional Arguments, Numer. Methods Partial Differential Eq., 27, 447-459, doi.org/10.1002/num.20532, (2011).

[16] Yüzbaşı Ş., Laguerre approach for solving pantograph-type Volterra integro-differential equations, Applied Mathematics and Computation, 232, 1183?1199, doi.org/10.1016/j.amc.2014.01.075, (2014).

[17] Kürkçü Ö.K., Aslan E., Sezer M., A numerical approach with error estimation to solve general integro-differential?difference equations using Dickson polynomials, Applied Mathematics and Computation, 276, 324?339, doi.org/10.1016/j.amc.2015.12.025, (2016).

[18] Oğuz C., Sezer M., Chelyshkov collocation method for a class of mixed functional integro-differential equations, Applied Mathematics and Computation, 259, 943?954, doi.org/10.1016/j.amc.2015.03.024, (2015). 